\title{
ACTION OF DIAZOANISOLE UPON PHENOLES.
}

\author{
By James H. Stebbins, JR., F. C. S.
}

SECOND PAPER.

In my last paper on this subject, I described a compound produced by the action of diazoanisole chloride, upon an alkaline solution of orcine.

At present it is my intention to describe a somewh.t similar body resulting from the union of diazoanisole ch.loride, and resorcine disulphonate of soda.

12. $3 \mathrm{~g}$. anisidine were diazotized with $17.9 \mathrm{~g}$. $\mathrm{FI} \mathrm{Cl}(1.20 \mathrm{Sp}$. Gr.) and $6.9 \mathrm{gr.} \mathrm{Na} \mathrm{NO}$, in $200 \mathrm{c.c}$ c. water.

The diazoanisole chloride thus formed, was added, little by little, and under constant stirring to a solution composed of $18.9 \mathrm{grs}$. resorcine disulpho acid, 16 grs. $\mathrm{Na} O \mathrm{OH}$ in 200 c. c. water, and 20 c. $\mathrm{c} . \mathrm{Na} \mathrm{OH}$ and $\mathrm{Aq}$. (10 per cent.)

The whole was allowed to rest for a few hours, and then treated with an excess of strong muriatic acid, which precipitated the dyestuff as a free acid.

It was then dissolved in hot water and allowed to crystallize.

Thus prepared it crystallizes in little fern shaped yellow plates, which are easily soluble in hot and cold water.

RESORCINE-DISULPHO ACID AZO-ANISOLE.

This substance is probably formed according to the following equation :

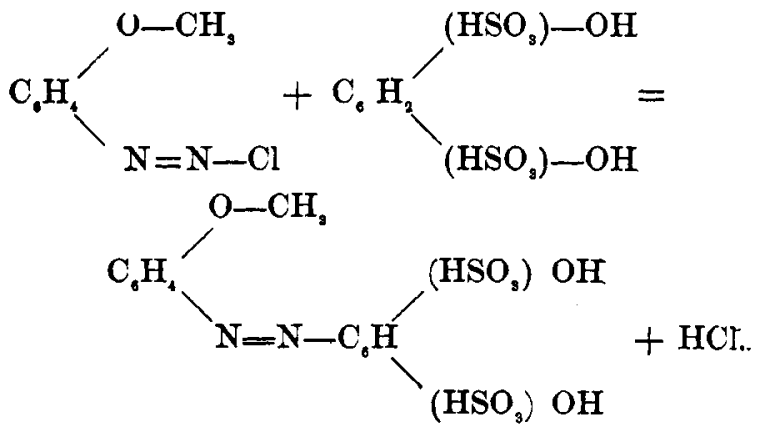




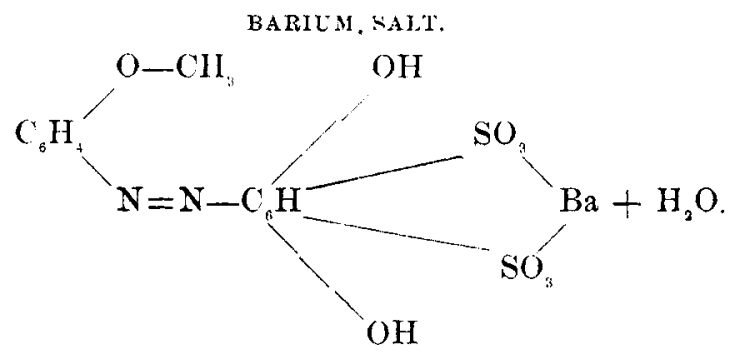

This interesting salt, was obtained, by dissolving the free acid in hot water and treating with an excess of $\mathrm{Ba} \mathrm{Cl}_{2}$.

The precipitate formed was collected on a filter, washed and dissolved in boiling water, from which it crystallized on cooling in fine, yellow, star-grouped needles.

In transmitted light this salt has a yellow color, but in reflected light a brick-red shade.

It is sparingly soluble in cold, but readily soluble in boiling water, from which it crystallizes with one molecule water of crystallization.

A barium estimation gave :

Barium

THEORY.

Barium

$.24 .56 \%$

\section{ON A NEW DEVICE FOR DETERMINATION OF CAR- BON IN CAST IRON.}

\section{By A. A. Brenemax, S. B.}

The carbonaceous residue obtained when cast iron is dissolved is commonly transferred with the mass of asbestos sering as a filter to the combustion tube. To avoid accidents incident to this transfer, and to ensure the combustion of refractory portions of graphite, the writer has adopted the modifications of the process described below. A brief note upon the process was read at the meeting of the American Association in 1879, but the success attending its use since then by students under the writer's direction, as well as the introduction of some minor improvements, has led him to believe that a fuller description of the process might be useful to others. The process depends in the main upon the use of combustion tubes of porcelain, and the employment of a small tube of platinum as a 